\title{
Randomization application: A new tool for academics of the new millennium
}

Thiago Guerino Amaral ${ }^{1}$, Tiago Braga ${ }^{2}$ DDS, Rodrigo Rodrigues Amaral ${ }^{* 2,3}$ DDS, MSc, PhD, Jane Evans² BFET, PhD, SFHEA.

${ }^{1}$ Merrimac State High School, Gold Coast, Queensland, Australia.

${ }^{2}$ School of Dentistry and Oral Health Griffith University, Gold Coast, QLD, Australia.

${ }^{3}$ Department of Dentistry, Pontificia Universidade Católica, Belo Horizonte, MG, Brazil.

\section{Disclosure:}

The authors deny any conflicts of interest

Corresponding author address: Rodrigo Rodrigues Amaral

Griffith Health Centre, Corner Olsen Avenue \& Parklands Drive, Gold Coast campus

Southport, QLD 4215, Australia.

School of Dentistry and Oral Health Griffith University.

Telephone $+61(0) 405952039$

Email: r.amaral@griffith.edu.au 


\section{Randomization application: A new tool for academics of the new millennium}

\section{PROBLEM}

Learning is no longer centered around the 'sage on the stage'; rather students are partners in the learning process. ${ }^{1}$ As academics, we have the responsibility to innovate our approach to learning and teaching by applying new approaches.

Randomization is a method of experimental control that has been applied to biological experiments and human clinical trials, provide equitable treatment allocation and valid statistical inference. ${ }^{2}$ Also, using randomization in a classroom environment can increase student participation and engagement; however, most of the time, it is done in rudimentary ways, such as using pieces of paper. This inconvenient, underdeveloped, and time-consuming method might prevent educators from using randomization in their classes; hence, a mobile application could bring innovation to this process and, consequently, increase class performance.

Although several randomization programs are available, ${ }^{3}$ the majority are desktop applications, commercial software, or web applications that might be inaccessible from some locations or unaffordable for investigator-initiated trials where study subjects need the assignment. However, according to the Pew Research Center (2020), the vast majority of Americans, nearly $96 \%$, own a cellphone. ${ }^{4}$ As mobile touch devices continue to grow, applications (apps) are replacing traditional communication technology and are becoming an indispensable part of academic life. 


\section{SOLUTION}

The RandomIZE App was primarily designed to streamline randomization processes in research; it is also an easy-to-use tool for educators to make classes more engaging. One of its main strengths in research is providing strict double-blind experiments - vastly used in clinical trials, limiting experimenter biases or behavior change, hence preventing the Hawthorne effect. ${ }^{2}$

The App avoids random errors by precisely programming random assignments and using two standard randomization techniques: simple randomization and block randomization. The first is used in functionalities such as a random number generator, a list randomization tool, random number table, dice, and heads or tails. In comparison, the latter is used in the group generator, which allows the randomized and balanced distribution of groups (Figure 1).
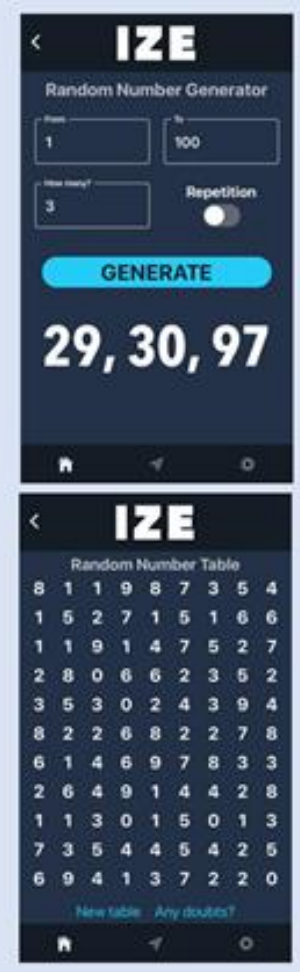
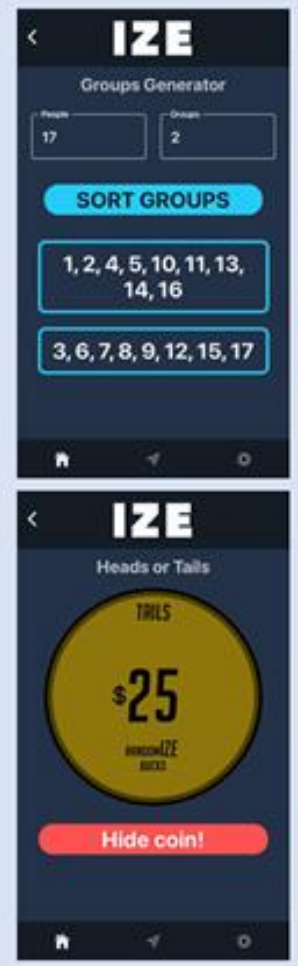
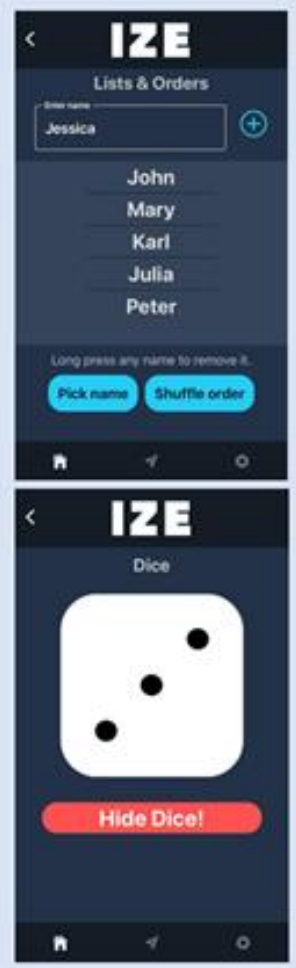

Figure 1. Randomization Tools in the App. 
In addition to the aforementioned use in research, the application can also be applied to education. Educators who embrace contemporary approaches demonstrate innovation. Hence those who use the App to introduce randomization in their classes are likely to retain more engagement.

The RandomIZE mobile application is available for free in the Apple App Store and Google Play Store. ${ }^{5}$

\section{RESULTS}

The RandomIZE App was successfully used to randomly assign patients to different groups in the "Quantitative assessment of the efficacy of two different single-file systems in reducing the bacterial load in oval-shaped canals: A clinical study". This article was recently published in the Journal of Endodontics https://doi.org/10.1016/j.joen.2020.06.007.

Although the App was released 12 months ago, there has been a remarkable acceptance of the RandomIZE App worldwide. According to data from the Google Play Store, there has been a steady increase in downloads from the date the App was released (Figure 2).

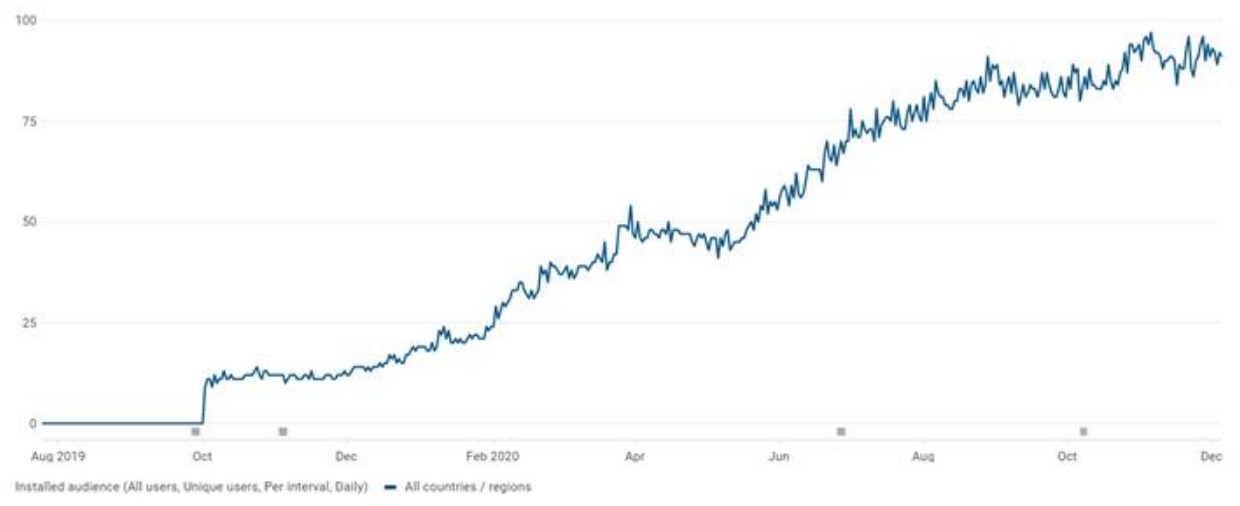

Figure 2. Google Play Store Downloads through Time. 
Apple store shows there were 856 downloads during the past 90 days (Figure 3).
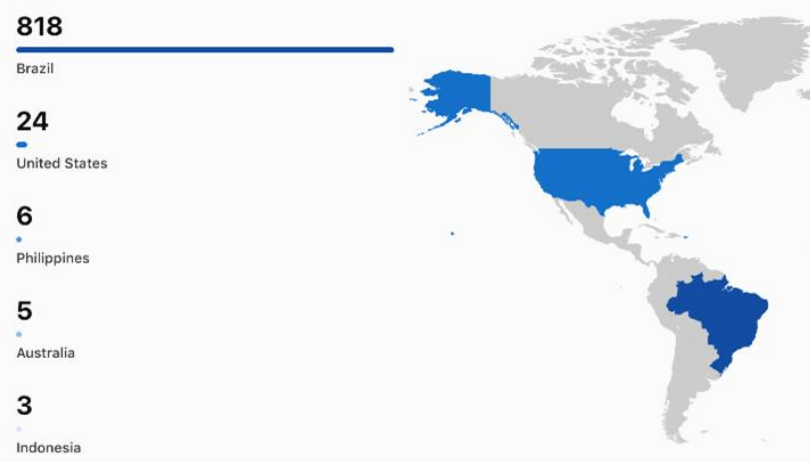

Figure 3. Apple App Store Worldwide Downloads.

The App has been fostering academics of the new millennium. Further feedback and engagement would enable improvements to the App.

\section{ACKNOWLEDGMENTS}

This study was financed in part by the Coordination for Improvement of Higher Education

Personnel (CAPES), Brazil. Finance Code 001.

The authors are grateful for the support from the Pontifical Catholic University of Minas Gerais.

\section{DISCLOSURE}

The authors deny any conflicts of interest 


\section{REFERENCES}

1. Morrison, Charles D. "From 'Sage on the Stage' to 'Guide on the Side': A Good Start," IJ-SoTL. 2014; 8(1):1-15. Article 4.

2. McCarney, R., Warner, J., Iliffe, S., van Haselen, R., Griffin, M., \& Fisher, P. The Hawthorne effect: A randomised, controlled trial. BMC Med Res Methodol. 2007;7(3) 30.

3. Saghaei M. An overview of randomization and minimization programs for randomized clinical trials. J Med Signals Sens 2011;1(1): 55-61.

4. Pew Research Center. 2020. Available at: Mobile fact sheet. http://www.pewinternet.org/factsheet/ mobile/ Accessed November 19, 2020.

5. RandomIZE App available at:

https://apps.apple.com/au/app/randomize-randomization-tool/id1490735869

https://play.google.com/store/apps/details?id=com.thiagoamaral.randomIZE\&hl=en 